\title{
Invoking human rights to stop ivory tower bullies
}

Higher education institutions are not immune to workplace bullying. In fact, research virulent breeding grounds for a particularly pernicious form a particularly pernicious form popular perceptions of civility. In higher education, bullying is even delegated to subordinates. However, because workplace bullying inhabits a grey legal area, prosecuting cases is challenging. Dr Leah $P$ Hollis at Rutgers University, New should re-examine the socia position of bullying from the perspective of the foremost authority on such matters: the Universal Declaration of Human Rights.

-or those caught in the continual hallowed halls of higher education may seem a genteel place to work. A caries icated to learning and instruction reflection and respectful repartee with peers and students. The reality is different. Academia is highly competitive and uncompromising, and history has endowed it with a hierarchy that resists forces calling for its overhaul. Positions are protected, and the climb to tenure academia's version of total job security - requires political game-playing and negotiating its many unwritten rules. As a result, higher education can be a breeding ground for a malignant type of bullying that spreads below an epiderm of respectability. However, one specialist in studying workplace bullying is invoking Rights to get academic instivans stop bullying in its tracks.

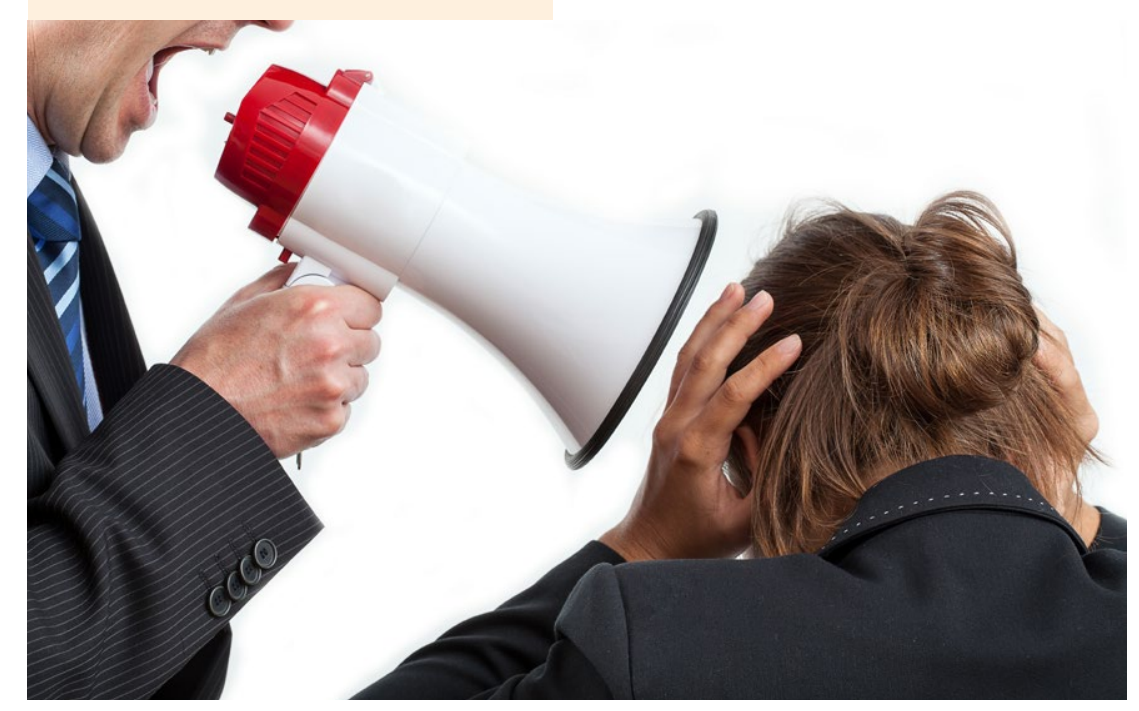

Dr Leah P Hollis is a visiting scholar at Ruf in higher education including The coercive community college: Bullying and its costly impact on the mission to senve underrepresented populations and Human Resources Perspectives on Workplace Bullying in Higher Education. Both books focus on structural issues that support bullying. In 2019, in the Journal for the Study of Postsecondary and Tertiary Education, Hollis published a particularly illuminating piece of research highlighting a hitherto ignored area of study. Titled The Abetting Bully: Vicarious Bullying and Unethical Leadership In Higher Education, it drew attention to some of the more insidious and elaborat forms of bullying - where bullies use creating an as art of their powerp system that is difficult to detect a

\section{T'S ALL ABOUT POWER}

By definition, workplace bullying, such as that in higher education, is primarily based on a power differential. The bully typically has power over the target, and uses that power to demoralise those who cannot fight back. As such, workplace bullying differs from abuse rooted in racism or sexism because it can exist within a homogenous social environment - women can bully other women, African Americans other African Americans. This makes it harder to prosecute. For example, in the United States, any legislation that could be used to prosecute workplace harassment takes

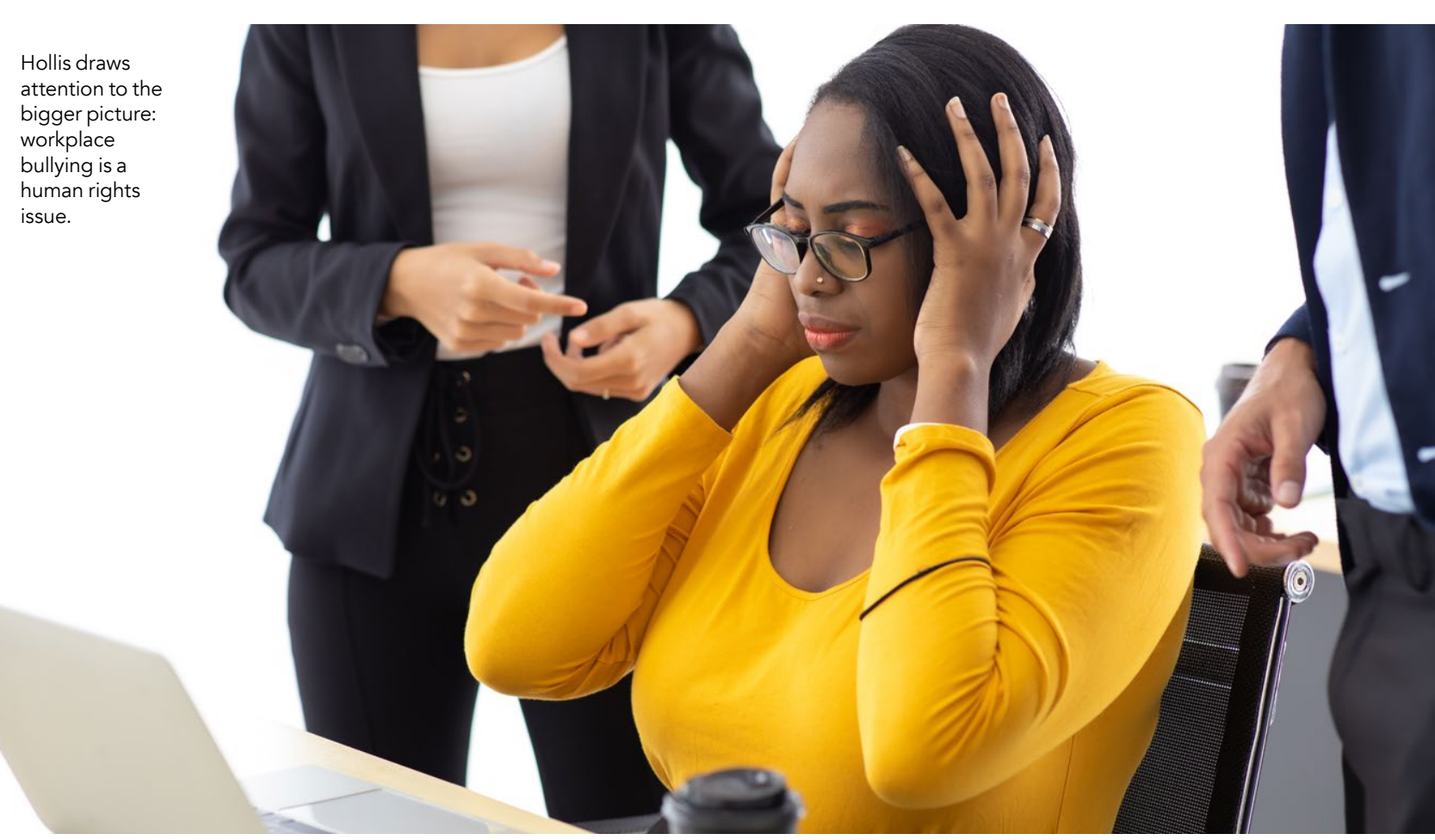

which prohibits harassment based on a $\quad$ higher education bullies and their national origin, sexual orientation, and disability. This means the legal grounds are a little grey when, for example, a v executive administrators, and the path to power becomes evident for those lower down the ranks. Thus, bullying is baked into the system.

woman junior researcher

Dr Hollis' research has uncovered an intricate web of bullying in higher education that capitalises on this blurred legal status. It typically flows down the The outcomes of higher education bullying are more than systematic harassment. Hollis points to the wealth of research that has catalogued the very

discourages collaboration and teamwork and incentivises sick leave.

THE GENDER AND RACE SKEW In her own study of vicarious bullying United States, Hollis was particularly interested in how it affected women and women of colour - African American women, Hispanic/Latina women, Native American women, and Asian/Pacific Islander women.

tenured faculy nonfauly staft. manifests itself Workplace bullying differs from abuse rooted in racism or sexism because it can exist within a homogenous social environment - women can bully other women, African Americans other allocation of unruly classes, last-minute class assignments, unjustified

expectations of service, and minute-byminute accounting of time. It is also less subtly delivered through shouting and insults. To a large degree, the faculty are the income generators for any higher education institution - they bring in the grants, the scholarships, and the feepaying students. Therefore, they enjoy protected status - senior administrato Pentiont

African Americans.

victims of bullying endure, including post-traumatic stress, panic attacks, insomia, suicide ideation, heart disease, and diabetes. But the victims are not the only sufferers. Witnesses of bullying and depression. There are broader that fail to stop bullying in that fail to stop bullying, inclualing high placements. A hostile work environment
She questioned 729 level administrators such as directors, executive directors, vice presidents, as well as senior faculty members, including assistant professors, associate professors, he respondents, 498 were women. The tudy is particulanly pertinent - as and people of colour often are in the least powerful positions, they are more likely to face workplace bullying.

Among the key insights from Hollis study was that $58 \%$ of the respondents bullying bither as a victim workplace and 42\% sid they had been tevitim 


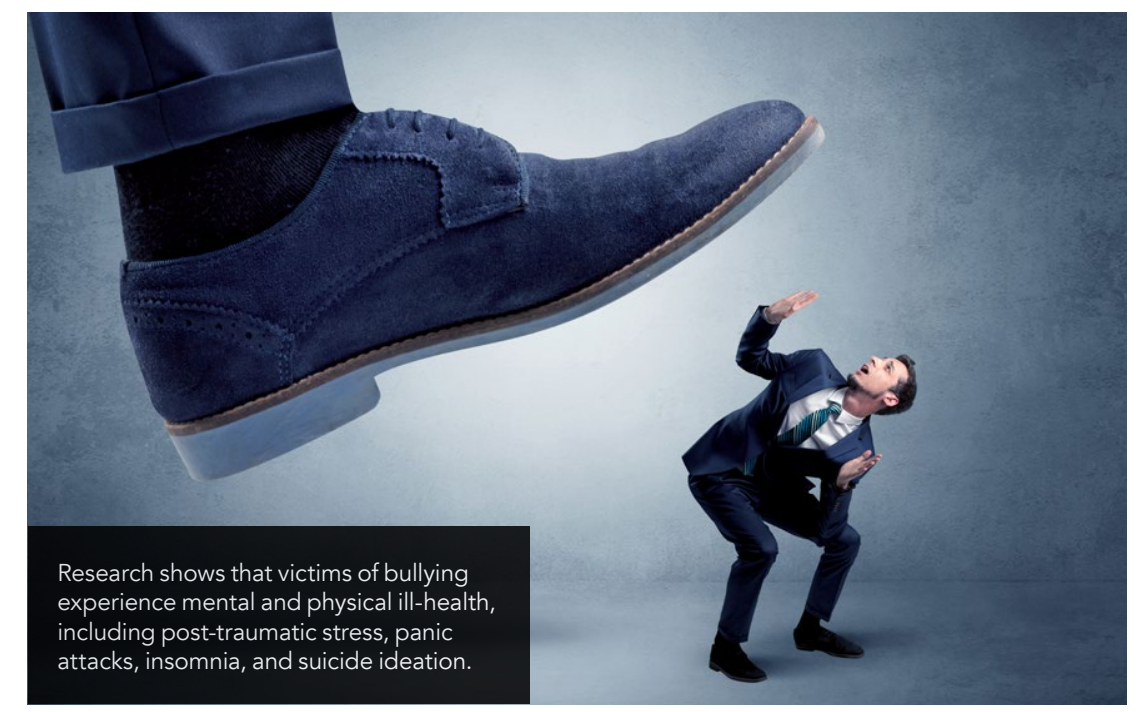

The need for higher education to countervail human rights violations has never been more vital.

\section{of vicarious bullying - when a more} senior person sent a subordinate to do the bullying. Considering gender, as Hollis hypothesised, proportionaly. women were more likely to face vicarious bullying; however, Hollis had even more so for women of colour. The data show that women are more likely to make career decisions to avoid workplace abuse and leave an education institution because of bullying

\section{UPPING THE ANTE} Hollis has decided to up the ante by drawing attention to the bigger picture workplace bullying is a human rights issue. In a paper in the journal Policy Futures in Education titled Universa Declaration of Human Rights: An argument for higher education to prohibit workplace bullying, Hollis argues that workplace bullying is

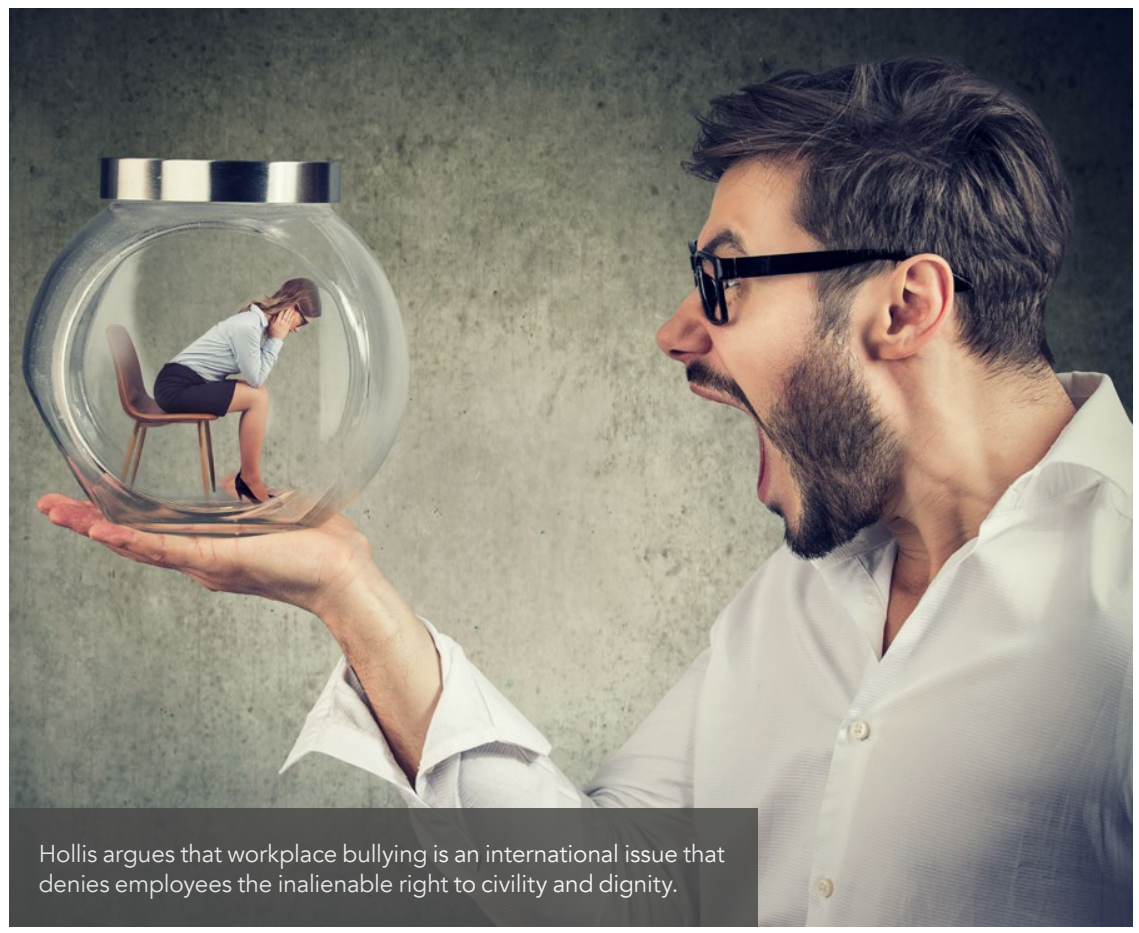

an international issue that denies

Drawing on research into bullying in higher education worldwide, including in South Africa, Turkey, Taiwan, Japan, the United States, the United Kingdom, Australia, and Nigeria, Hollis points out that workplace bullying is not limited to members of any protected group class status. It is a human rights violation in its own class. She also points to the reams of research showing how workplace bullying permanently affects employees' physical and mental health and destroys productivity. She quotes research from New Zealand that claims temimics domestic abuse. It is endemic everywhere, and rare effors to control wrod hational legistation haven't in Sweden in 1993 placed the responsibility on supervisors to report and curtail bullying: little solace for subordinates bullied by supervisors.

Hence, Hollis invokes the Universal Declaration of Human Rights, specifically the affirmation that 'all human beings are born free and equal in dignity and rights, no one shall be subjected to torture or to cruel, inhumane or degrading treatment' and 'all are equal before the law and entitled without discrimination to equa protection.' Given the clarity of the decree, and the unequivocal evidence that workplace bullying is cruel and degrading, it is hard to argue that it rights at an international level.

That it is so widespread in higher education presents a disturbing level of irony. Colleges and university campuses are supposed to be bastions of diversity and human rights ideologies. Furthermore, they have been the intellectual ignition points for social change on human rights matters, think opposition to the Vietnam War, fighting apartheid in South Africa, and calls for democratic reform in China. Hollis is calling for higher education institutions to now use that same ethical compass to steer their passion and focus inwards. In herwords: the need for higher education to countervail human rights

\section{A Behind the Research Dr Leah P Hollis}

E: equity1@diversitytrainingconsultants.com T: +1 016109906588 W: www. diversitytrainingconsultants.com

\section{Research Objectives}

Leah P Hollis is an international expert on workplace bullying. Her book, Human Resources Perspectives on Worklace Bullying in Higher Education (2021) examines structural issues that support workplace bullying.

\section{Detail}

\section{Address:}

2207 Concord Pike \#238

Wilmington DE 19803

Bio

DrLeah P Hollis is a visiting professor at the Samuel Dewitt Proctor Institute for Leadership, Equity and Justice at Rutgers University in New Brunswick, New Jersey in the US, and associate professor at Morgan State University in Baltimore, Maryland. She earned her EdD from Boston University as a Martin Luther King, Jr fellow for social justice. She is an international expert on workplace bullying and the author of The Coercive Community College: Bullying and its Costly Impact on the Mission to Serve Underrepresented Populations, Bully in the lvory Tower. How Aggression and Incivility Erode American Higher Education, which is based on independent research Persp coctiveses and universities, and Human Resource Perspectives an Work lace Bulying in Higher Education.

\section{UNIVERSAL DECLARATION} OF HUMAN RIGHTS

\section{References}

Hollis, LP, (2021) Universal Declaration of Human Rights: An argument for higher education to prohibit

Hollis, LP, (2019) The abetting bully: Vicarious bullying and unethical leadership in higher education. Journal for the Study of Postsecondary and Tertiary Education, 3, 1-18. doi. org/10.28945/4255

Hollis LP, (2015) Bully university? The cost of workplace bullying and employee disengagement in American higher education. Sage Open, 5(2), doi. org/10.1177/2158244015589997

\section{Personal Response}

What is needed for more higher education institutions to realise that workplace bullying is a human rights issue?

II Ideally, higher education leadership should be empathetic to the pain and anxiety that targets of workplace bullying suffer. If an empathetic perspective does not motivate leadership, then the exorbitant cost of $\$ 9,600$ ee the abse motivation, higher eduction may operate like the K-12 sector regarding bullying The tragic Columbine shooting in 1999 which left 15 dead, was the start of a movement to strictly prohibit bullying in schools. Now, all 50 states have passed legislation to prohibit K-12 bullying II 